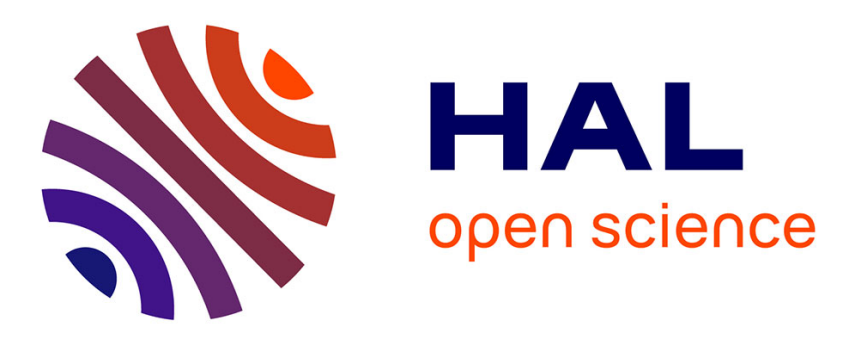

\title{
Influence of sample thickness and experimental device configuration on the spherical indentation of AISI 1100 steel
}

Philippe Brammer, Gerard Mauvoisin, Olivier Bartier, Xavier Hernot, Simon-Serge Sablin

\section{To cite this version:}

Philippe Brammer, Gerard Mauvoisin, Olivier Bartier, Xavier Hernot, Simon-Serge Sablin. Influence of sample thickness and experimental device configuration on the spherical indentation of AISI 1100 steel. Journal of Materials Research, 2012, 27 (1), pp.76-84. 10.1557/jmr.2011.247 . hal-00996375

\section{HAL Id: hal-00996375 \\ https://hal-univ-rennes1.archives-ouvertes.fr/hal-00996375}

Submitted on 26 May 2014

HAL is a multi-disciplinary open access archive for the deposit and dissemination of scientific research documents, whether they are published or not. The documents may come from teaching and research institutions in France or abroad, or from public or private research centers.
L'archive ouverte pluridisciplinaire HAL, est destinée au dépôt et à la diffusion de documents scientifiques de niveau recherche, publiés ou non, émanant des établissements d'enseignement et de recherche français ou étrangers, des laboratoires publics ou privés. 


\title{
Influence of sample thickness and experimental device configuration on the spherical indentation of AISI 1100 steel
}

Philippe Brammer ${ }^{\mathrm{a}, \mathrm{b}}$, Gérard Mauvoisin ${ }^{\mathrm{a}}$, Olivier Bartier ${ }^{\mathrm{a}}$, Xavier Hernot ${ }^{\mathrm{a}}$ and Simon-Serge Sablin ${ }^{\mathrm{b}}$

${ }^{a}$ L.A.R.M.A.U.R-Indentation, E.A. 42.82, Bât 10B, Université de Rennes 1, Campus de Beaulieu, 35402 Rennes Cedex, France

${ }^{\mathrm{b}}$ Technocentre Renault, Research Advanced Studies and Materials Engineering (DREAM) Material Engineering Department (DIMat), 1 avenue du Golf, 78288 Guyancourt cedex, France

\begin{abstract}
Most instrumented indentation theoretical studies and models consider bulk sample geometry, which implies no influence on the indentation response. In the particular case of thin samples, our previous studies have shown that the thickness has an influence on the experimental device behaviour as well as on the sample and material response. This work is a numerical and experimental illustration of this particularity. Spherical macroindentation tests are performed on AISI 1100 steel samples of thicknesses varying from 10 to $0.55 \mathrm{~mm}$. Experimental and numerical results are compared. Experimental limitations are investigated and solutions to obtain results which are independent of the sample thickness and curvature are proposed. We show that the proposed solution, which is the object of an international patent, leads to a reliable identification of the material mechanical properties of thin and moderately bent samples.
\end{abstract}

KEYWORDS: Instrumented indentation, sample thickness, FEM 


\section{INTRODUCTION}

The spherical indentation test data is obtained by continuously measuring the applied load $F$ and penetration depth $h$ of a stiff spherical indenter of radius $R$ in the surface of the tested material. Concerning metallic alloys, recent studies have shown that the data from a single spherical indentation test has the potential to evaluate a unique solution for the Young modulus as well as for the two parameters of the Hollomon hardening law, especially if sufficiently deep normalized penetration $h / R$ is achieved in the case of materials which are difficult to differentiate. ${ }^{1,2}$ The spherical indentation test has been widely used to evaluate the mechanical properties of bulk materials ${ }^{6-16}$, treated surfaces and coatings ${ }^{3-5}$ by computer assisted inverse analysis. Some studies have also considered anisotropic materials and proposed to use the geometry of the residual imprint as additional information. ${ }^{17,18}$

The main advantages of the indentation test compared, for instance, to the tensile test, are the local probing of mechanical characteristics and the few restrictions on the sample shape and size. However, most of the theoretical and numerical models proposed so far consider infinite sample dimensions compared to the indenter radius, which implies no influence on the indentation response. The few studies on metallic sheets also consider the thickness to be high enough to have no influence. ${ }^{19}$ In the present study, the influence of the sample thickness is the focus of attention. This work aims at an increased understanding of how the indentation test can be applied to thin metallic sheets in the automotive industry.

In section II, the studied material, samples and indentation device specificities are described as well as the patented ${ }^{21}$ solution of the Universite de Rennes 1 which consists in using a spherical anvil instead of a classical flat anvil in the case of thin samples which exhibit a slight curvature. In section III, the numerical model and resulting observations are presented. In section IV, experimental results are presented. Section V provides a summary of the present work as well as prospects for further work. 


\section{MATERIAL AND EXPERIMENTAL DEVICE DESCRIPTION}

\section{A. Material, sample preparation and characterisation}

The selected sample for this study is a spheroidized AISI 1100 steel. This type of steel was selected in order to obtain a fine and homogeneous microstructure and thus a good reproducibility of the indentation tests. Fig. 1(a) represents the microstructure of the AISI 1100 steel and shows a homogeneous distribution of spheroidized cementite particles in a ferritic matrix.

Tensile tests were performed on samples issued from the same rod as the indentation samples. The test led to the stress-strain curve shown figure 1(b).

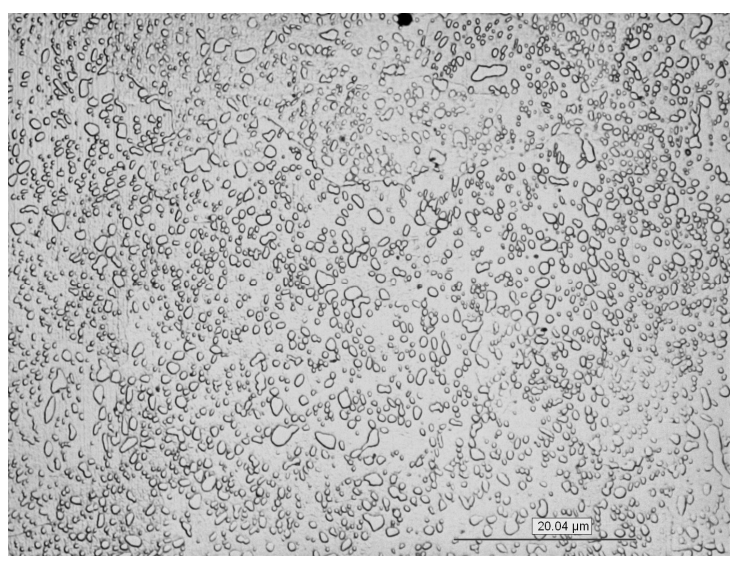

(a)

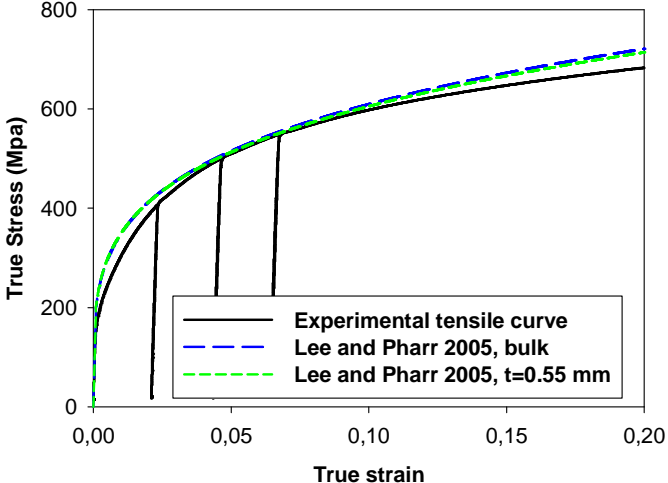

(b)

FIG. 1. (a) Microstructure and (b) stress-strain relationship of the studied AISI 1100 steel

Indentation samples were cut out of the same rod and were rectified to the thicknesses $10,1.9,1.5,1.0$ and $0.55 \mathrm{~mm}$. Then, the specimens were carefully polished using fine emery papers (up to 1200 grit) and diamond suspensions ( $6 \mu \mathrm{m}$ and $3 \mu \mathrm{m}$ ) to avoid uncertainties due to roughness. 


\section{B. Indentation device specificities}

The indentation tests were conducted with a bulk WC indenter of approximate radius $0.5 \mathrm{~mm}$, up to a load of $200 \mathrm{~N}$. Indentation loading was controlled such that the loading rate was held constant at $0.2 \mu \mathrm{m} / \mathrm{s}$. The indentation depth is measured by a set of three sensors at a distance of $10 \mathrm{~mm}$ from the indentation axis.

\section{Bulk indentation}

Indentation tests performed on a bulk $10 \mathrm{~mm}$ thick AISI 1100 sample show a very good reproducibility, as shown in Fig. 2. A calibration procedure for the indenter was applied and the Hollomon power law parameters were evaluated using the model proposed in 2005 by Lee and Pharr. ${ }^{8}$ The results presented in Fig. 1(b) show a good agreement between the experimental and the evaluated hardening curve. The finite element method (FEM) results are discussed in section III.

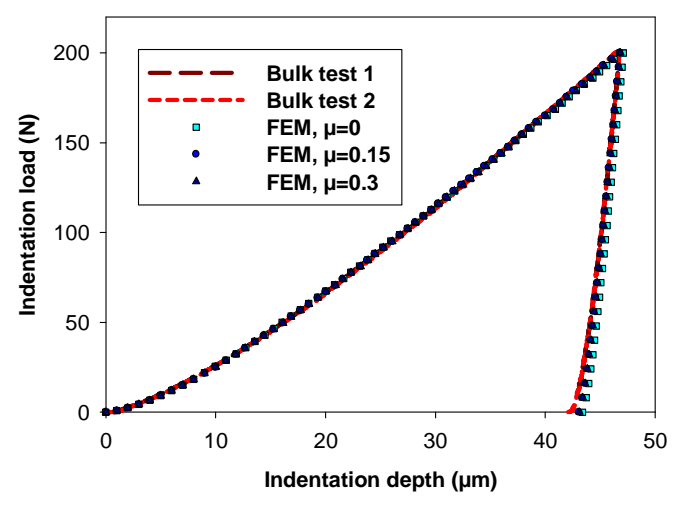

FIG. 2. Indentation curves on bulk AISI 1100 steel

\section{Spherical anvil}

It is expected, as will be presented in section IV, that reproducibility problems can be encountered due to the unavoidable curvature of thin samples. Instead of a classical flat anvil, our proposition is the use a spherical anvil which radius must be smaller than the sample curvature, but high enough not to influence the indentation results. For this purpose, a bulk 
WC anvil with a rounded tip of high radius is used. Indentations were performed on a high yield stress steel bulk sample and the resulting elastic contact curve was used to evaluate the tip radius $R$, which is difficult to measure optically. We used the Hertz contact solution ${ }^{20}$ which provides the relation between the load $F$ and the mutual approach $h$ of two points far from the contact zone in two infinite half-spaces, i.e.:

$$
F=\frac{4}{3} E_{\text {contact }}^{*} \sqrt{R} h^{3 / 2}
$$

Where $E_{\text {contact }}^{*}$ is the reduced elastic modulus of the contact expressed as:

$$
\frac{1}{E_{\text {contact }}^{*}}=\frac{1-v_{\text {sample }}^{2}}{E_{\text {sample }}}+\frac{1-v_{\text {anvil }}^{2}}{E_{\text {anvil }}}
$$

Using a Young modulus of $210 \mathrm{GPa}$ for steel and $600 \mathrm{GPa}$ for tungsten carbide, and a Poisson ratio of 0.3 for steel and 0.22 for tungsten carbide, the experimental curve was found to be representative of the behaviour of a $140 \mathrm{~mm}$ radius sphere, as shown in Fig. 3. This radius value is thus considered in the present study for the spherical anvil. Numerical results are discussed in section III.

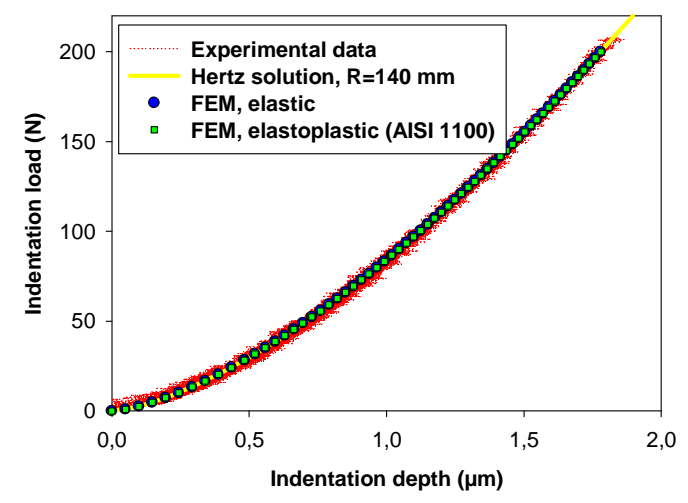

FIG. 3. Indentation curves with the spherical anvil used as an indenter 


\section{NUMERICAL AND THEORETICAL ANALYSIS}

The ABAQUS/Standard finite element code was used for the simulations, in axisymmetric mode. The geometries of the three bulk tungsten carbide tools, i.e. the indenter of approximate radius $0.5 \mathrm{~mm}$, and either the flat anvil or the spherical anvil of radius 140 $\mathrm{mm}$, were accurately reproduced. The four sample thickness values were simulated. All mesh elements are axisymmetric 4-node fully integrated elements. The element density distribution was built in order to obtain a compromise between accuracy in the contact and plastic zones, and computing time, as shown in Fig. 4.
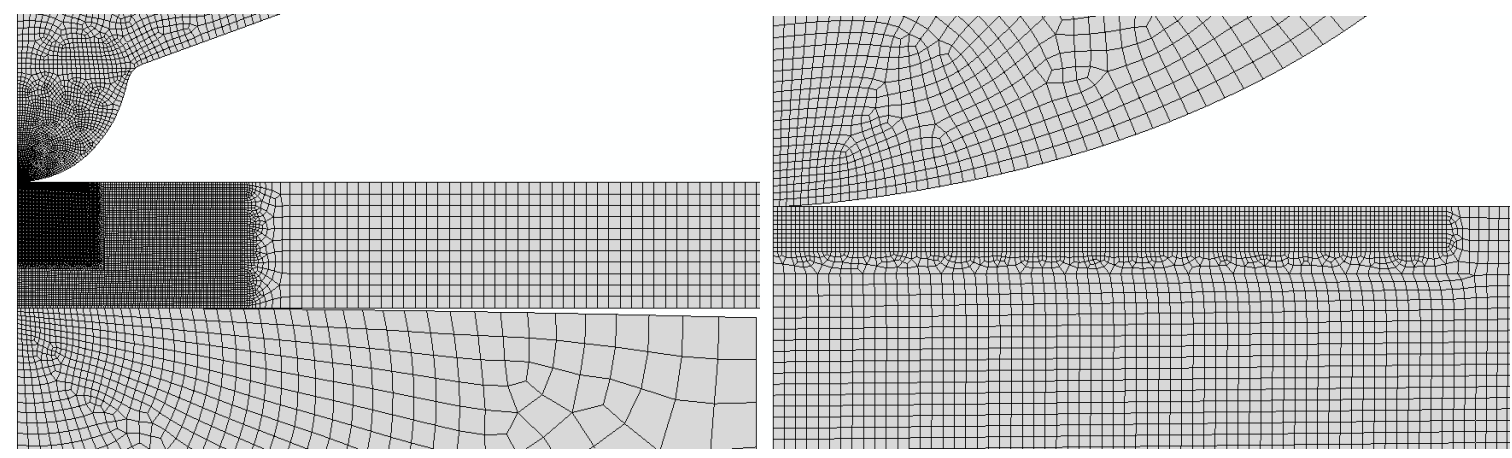

FIG. 4. Detail of the mesh in the contact zone

The sample material was assumed to obey isotropic linear elastic behaviour, with a Young modulus of $210 \mathrm{GPa}$ and a Poisson coefficient of 0.3 . The plastic behaviour was assumed isotropic and the chosen yield criterion was von Mises. The isotropic hardening curve was taken to be the experimental tensile curve from which the elastic deformation is removed, and the yield stress was determined using the standard $0.2 \%$ deformation criterion. The tungsten carbide Young modulus was set to $600 \mathrm{GPa}$, and its Poisson ratio to 0.22.

A penalty contact algorithm was used. Numerical simulations were performed on an infinite half space using friction coefficient values of $0.00,0.15$ and 0.30 in order to assess its influence. The resulting curves are shown in Fig. 2. The curve resulting from frictionless contact is slightly softer than those corresponding to friction coefficient values of 0.15 and 0.30, which are very similar. Numerical curves show very good agreement with the 
experimental curves on a bulk sample if a friction value is taken into account. Thus, the medium value 0.15 was used in the following simulations. This value is frequently used for the simulation of indentation between steel and tungsten carbide during deep indentation. ${ }^{10,11,16}$ The indentation of an infinite half space by the spherical anvil was also simulated using a friction coefficient of 0.15 , leading to the results shown in Fig 3 . The results are in very good agreement with the experimental result as well as the theoretical result. Note that the influence of the slight plasticity occurring in the AISI 1100 steel due to this contact is negligible.

Before analysing the indentation curves, it is worth noticing the particular behaviour of the sample and the experimental device in the case of the lowest thickness, i.e. $0.55 \mathrm{~mm}$. In Fig. 5, the upper surface of both anvils and the lower surface of the sample are drawn at maximum load and at the end of unloading, which provides the reference geometry of the tools. In the case of a flat anvil, the sample is pushed down on the indentation axis due to the anvil deformation and its outer region is raised at highest load, which inevitably affects the penetration measurement done at a distance of $10 \mathrm{~mm}$ from the axis. After unloading, the sample keeps an irreversible shape leading to a gap between its lower surface and the anvil. In the case of a spherical anvil, the lower surface of the sample fits to the shape of the deformed anvil and a sample curvature is observed at highest load. After unloading, the global deformed shape is kept, i.e. a residual imprint and a residual curvature of the sample remain.
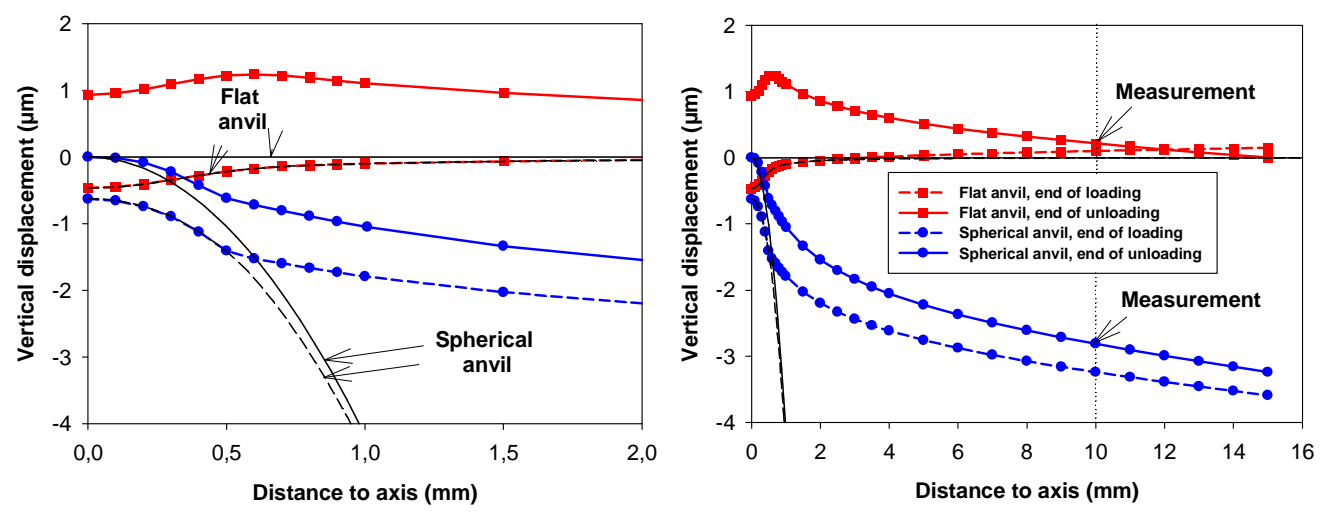
FIG. 5. Lower contact surface profiles at (a) low and (b) large scale

Due to the curvature of the sample when a spherical anvil is used, we decided to apply a second set of sensors underneath the sample. This technical trick was intended to provide results which are independent of the sample curvature. However, the measurement became dependant on the mutual penetration of the sample and the spherical anvil. This issue is considered thereafter.

Another aspect to take into account is the material response in the case of the thinnest sample. The von Mises stress and equivalent plastic strain values on the indentation axis at maximum load are plotted in Fig. 6(a) and Fig. 6(b) for the cases of bulk indentation and indentation on a $0.55 \mathrm{~mm}$ thick sample on either a flat or a spherical anvil.

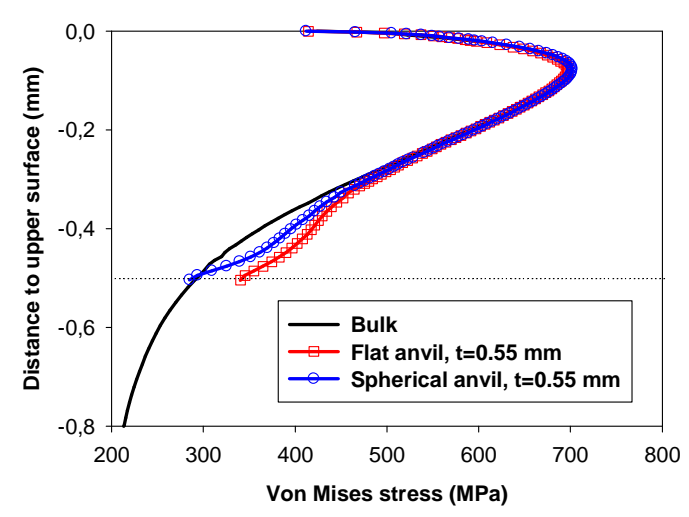

(a)

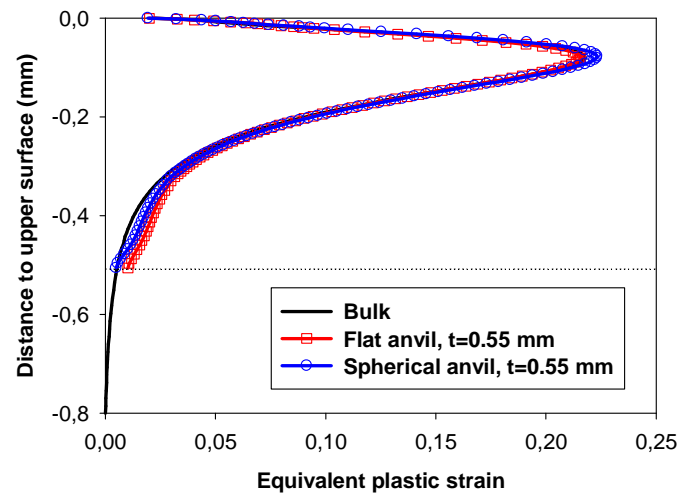

(b)

FIG. 6. (a) Von Mises and (b) equivalent plastic strain on the indentation axis at maximum

$$
\text { load }
$$

The values are quite similar, but a slight deviation from the bulk reference solution can be observed close to the lower surface of the thin sample. This deviation is greater in the case of a flat anvil then it is in the case of a spherical anvil. In both cases, von Mises stress and equivalent plastic strain values near the lower surface of the thin sample are higher than those occurring in a bulk sample at an equal distance to the upper surface. This can be due to the 
fact that part of the deformation would have been elastically accommodated in the case of a bulk sample, which would have led to lower stress and equivalent plastic strain values.

With these observations in mind, i.e. the particular behaviour of the experimental device, sample and material in the case of a thin sample, let us now consider the numerical indentation curves, which are compared to the numerical bulk indentation curve in Fig. 7.

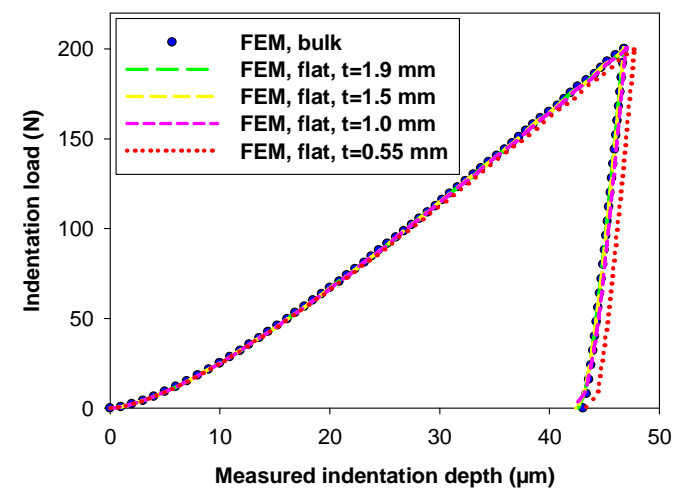

(a)

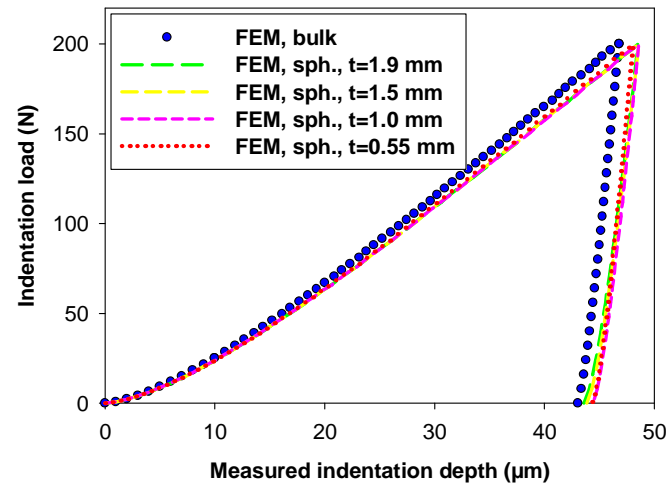

(b)

FIG. 7. Numerical curves for (a) flat and (b) spherical anvils

In the case of a flat anvil, no strong influence of thickness is noticed until a very low value, i.e. $0.55 \mathrm{~mm}$, is reached. The corresponding curve is softer. Part of this difference can be due to the deformation of the anvil which, even though stiffer than steel, is in contact with the specimen over a small area, and the rising of the measured point at $10 \mathrm{~mm}$ from the indentation axis. Both sources lead to an overestimation of the penetration depth into the sample. Another source can of course be due to the material which, as presented in Fig. 6, exhibits more plastic strain, thus a softer resistance to indentation when the sample thickness is low. The unloading curve remains unchanged, except at the very end of unloading when the effect of the gap mentioned through Fig. 5 can be seen.

In the case of a spherical anvil, all curves exhibit a softer response to indentation than the bulk indentation response. This is mainly due to the mutual penetration of the spherical anvil and the sample. Note that all loading curves except the one corresponding to the 0.55 
mm thick sample are very similar. Concerning the unloading curve, it is noticeable that the initial slope is different from the one observed in the case of bulk indentation, and that it depends on the sample thickness.

A great advantage of the spherical contact geometry is the availability of theoretical solutions. As presented in section II, the contact behaviour of the spherical anvil can be modelled by the Hertz contact solution using a $140 \mathrm{~mm}$ radius. Therefore, the contact radius $a$ can be expressed as:

$$
a=\sqrt[3]{\frac{3 F R_{\text {anvil }}}{4 E_{\text {contact }}^{*}}}
$$

And the contribution of the spherical anvil to the mutual penetration can be expressed as:

$$
h_{\text {anvil }}=\frac{3}{4} \frac{1}{E_{\text {anvil }}^{*}} \frac{F}{a}
$$

The particularity of the curve corresponding to the thinnest sample may be due to the fact that the sample cannot be considered as an infinite half space. Therefore, in a first approach, we propose to use a "truncated" form of the Hertz displacement field on the axis of indentation by integrating the deformation field down to the thickness $t$ of the sample, assuming that the Hertz stress field is still valid:

$$
h_{\text {thin sample }}=\int_{0}^{t} \varepsilon_{z}^{\text {Hertz }} d z=\frac{3}{2 \pi} \frac{1+v_{\text {sample }}}{E_{\text {sample }}} \frac{F}{a^{3}}\left(v_{\text {sample }} t a+\left(v_{\text {sample }}-1\right) a^{2} \arctan \left(\frac{t}{a}\right)-v_{\text {sample }} t^{2} \arctan \left(\frac{a}{t}\right)\right)
$$

The mutual approach of a point in the spherical anvil far from the contact and a point at the original sample surface is then taken as the sum of $h_{\text {anvil }}$ and $h_{\text {thin sample }}$. This value is removed from the measured displacement and the results are shown in Fig. 8: 


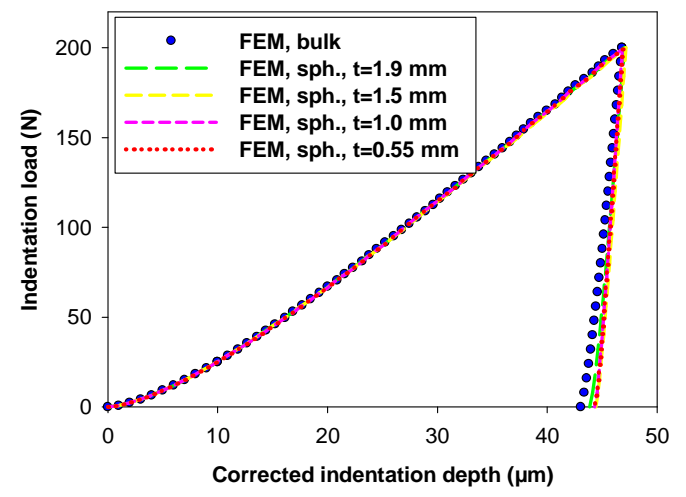

FIG. 8. Corrected curves on the spherical anvil

The corrected loading curves are very similar to the bulk indentation curve, even for the case of the thinnest sample. The reason for this good correction may be the fact that, once again according to Hertz's theory, maximum stress is at a depth value of $0.48 a$ for this material, and reaches the value $0.23 \mathrm{~mm}$ at maximum load, which is far from the sample thickness. The very slightly lower indentation load at highest indentation depths may once again be linked to the softer response of thin samples due to higher plastic strain. Concerning the unloading curves, the correction does not provide the bulk indentation behaviour and the slope is still dependant on the sample thickness. This can be attributed to the residual imprint on the lower surface of the sample, as shown in Fig. 5. 


\section{EXPERIMENTAL RESULTS}

Fig. 9. shows the experimental results obtained on the flat anvil at various sample thicknesses compared to the corresponding numerical solutions. Due to the lack of reproducibility of the experimental curves, they are fitted to the numerical solution at maximum load.

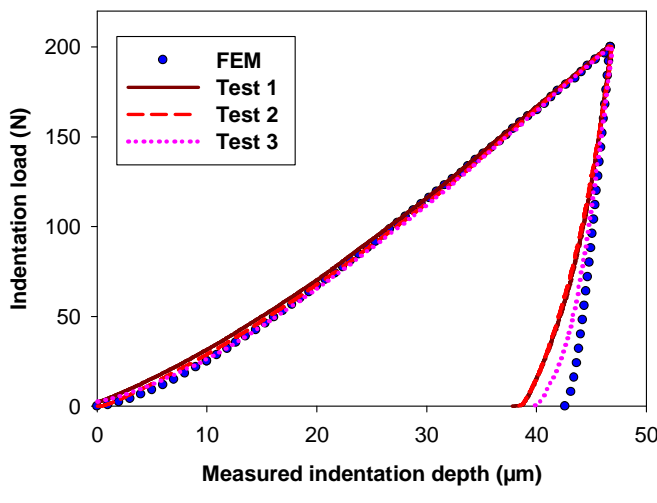

(a)

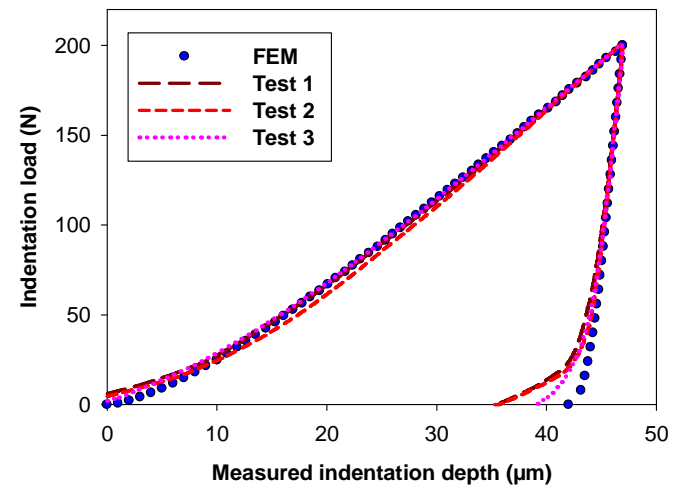

(c)

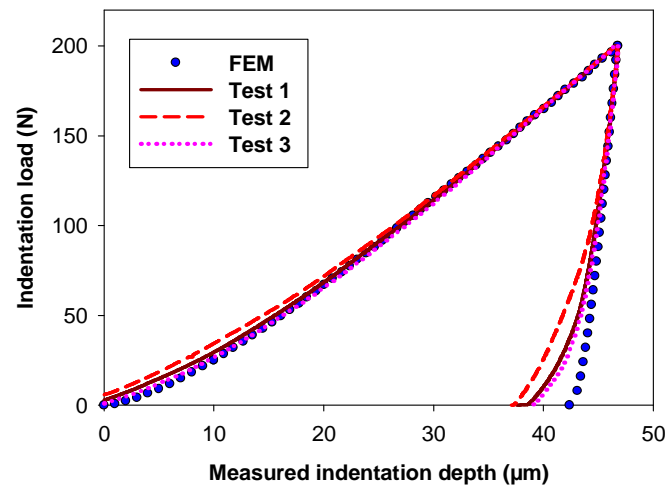

(b)

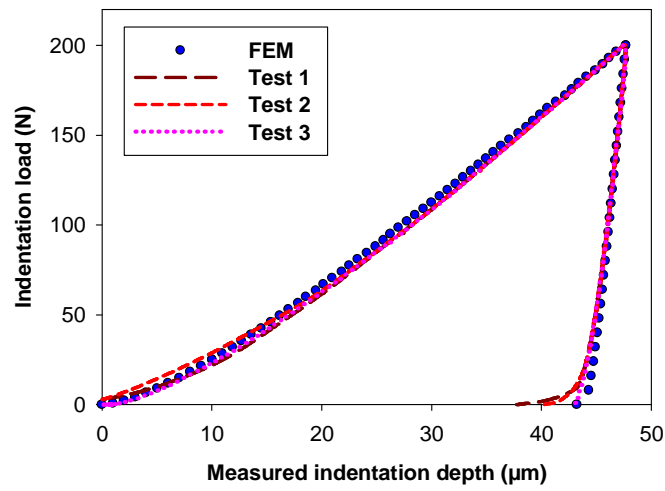

(d)

FIG. 9. Experimental curves on the flat anvil for sample thicknesses (a) $1.9 \mathrm{~mm}$, (b) $1.5 \mathrm{~mm}$,

$$
\text { (c) } 1.0 \mathrm{~mm}, \text { (d) } 0.55 \mathrm{~mm}
$$

It is clear that, compared to the reproducibility of the curves obtained on a bulk sample presented in Fig. 2, the experimental curves on a flat anvil exhibit a reproducibility problem, which is highlighted by the observation of the unloading curves. The however quite moderate reproducibility problem may be due to the fact that the samples were initially rectified with 
great care. If this reproducibility problem is due to the sample curvature, the less pronounced reproducibility problem in the case of a thin sample may be due to the lower stiffness of the sample at equal curvature.

Fig. 10. shows the experimental results obtained on the spherical anvil at various sample thicknesses compared to the corresponding numerical solutions.

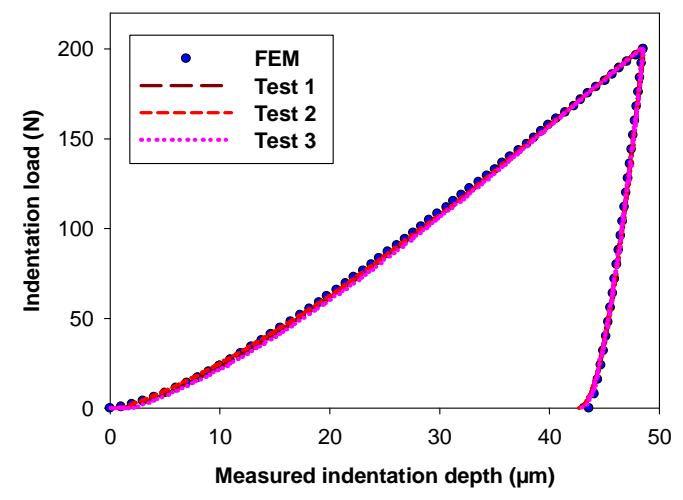

(a)

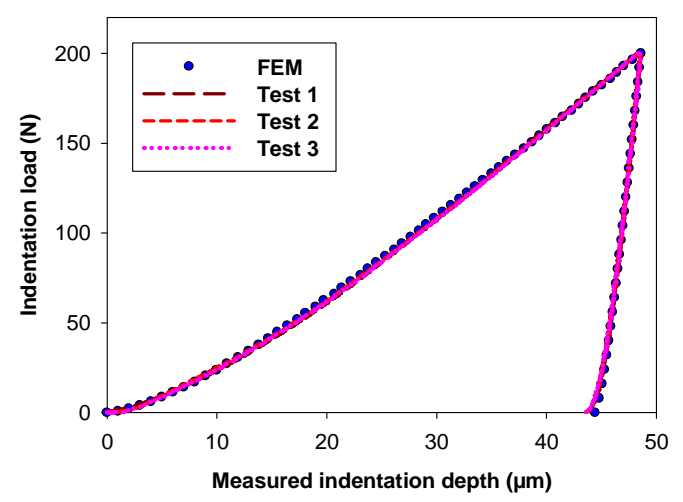

(c)

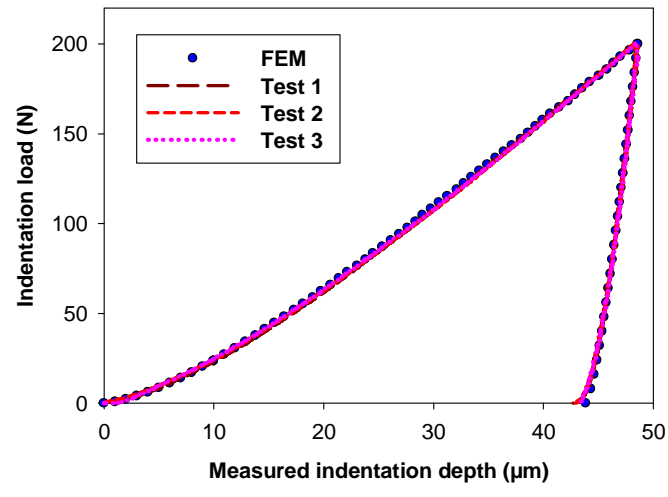

(b)

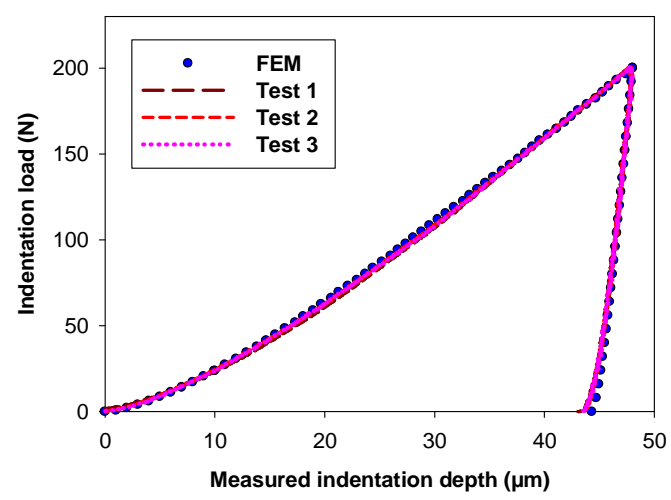

(d)

FIG. 10. Experimental curves on the spherical anvil for sample thicknesses (a) $1.9 \mathrm{~mm}$, (b)

$$
1.5 \mathrm{~mm}, \text { (c) } 1.0 \mathrm{~mm}, \text { (d) } 0.55 \mathrm{~mm}
$$

The results show a very good reproducibility as well as a very good agreement with the numerical solutions. This observation leads to the conclusion that the use of a spherical anvil provides results which are independent of the sample curvature. In order to confirm this conclusion, a $0.55 \mathrm{~mm}$ thick sample was slightly bent in order to present a curvature radius 
still higher than $140 \mathrm{~mm}$, defect which is not noticeable by eye. Indentation tests were performed on the flat and the spherical anvils. The results are presented in Fig. 11 (a).

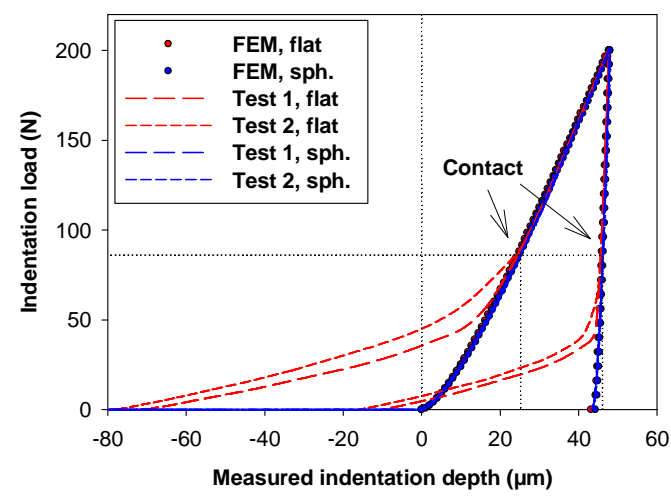

(a)

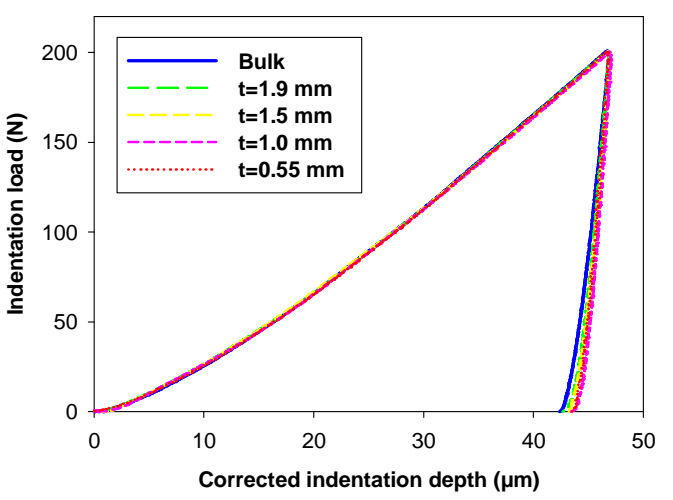

(b)

FIG. 11. (a) experimental curves on the bent sample and (b) corrected curves using a spherical anvil

The results show a very clear dependence on the sample curvature in the case of a flat anvil. The beginning of the curves is strongly affected until contact with the anvil on the indentation axis is established, whereupon the indentation behaviour is representative of the material. The unloading curves show the same dependency. In the case of a spherical anvil, the results are in no way affected. These observations lead to the conclusion that the use of a spherical anvil is a reliable solution in the case of slightly bent samples.

The Hertz transformation proposed in section III is applied to the experimental curves obtained with the use of a spherical anvil and the results are presented and compared to the bulk sample curve in Fig. 11(b). Observations are the same as for the numerical study. The corrected curves are very similar to the bulk sample curve, although slightly softer at highest load. The unloading curves show the same difference supposedly due to the residual imprint on the lower surface, as shown Fig. 5. Once again, the Lee and Pharr model ${ }^{8}$ is applied and provides the results in Fig.1(b), which, as expected, are very close to the curve evaluated from the bulk sample curve. 


\section{CONCLUSION}

In this work the influence of sample thickness and sample curvature on the instrumented indentation response was investigated. An AISI 1100 steel was characterized by tensile test. Spherical indentation tests were performed on a bulk $10 \mathrm{~mm}$ thick sample with an indenter of approximate radius $0.5 \mathrm{~mm}$ up to a load of $200 \mathrm{~N}$ in order to confirm the reproducibility and reliability of the results. The proposed spherical anvil radius was evaluated using theoretical elastic contact solutions.

Numerical simulations and experimental tests were performed on bulk, $1.9 \mathrm{~mm}, 1.5$ $\mathrm{mm}, 1.0 \mathrm{~mm}$ and $0.55 \mathrm{~mm}$ thick samples. Numerical results show that the sample thickness has an influence on the indentation device behaviour as well as on the sample and material response. While no correction theory is available on a flat anvil, elastic contact solutions are available in the case of a spherical anvil and can help largely recover the results obtained on a bulk sample. Experimental results show the strong influence of a slight sample curvature on the indentation curves obtained with a flat anvil. In the case of a spherical anvil, as long as the sample curvature radius is higher than the anvil radius, the indentation curves are not affected.

These observations lead to the conclusion that the use of a spherical anvil and adequate theoretical corrections are a relevant solution for the instrumented indentation of thin samples, especially if a sample curvature is expected, such as in the case of thin metallic sheets used in the automotive industry. 


\section{REFERENCES}

1 Y-T. Cheng and C-M. Cheng: Scaling, dimensional analysis, and indentation measurements. Mat. Sci. and Eng. R 44, 91 (2004).

2 X.Chen, N. Ogasawara, M. Zhaov and N. Chiba: On the uniqueness of measuring elastoplastic properties from indentation: the indistinguishable mystical materials. J. Mech. Phys. Solids 55, 1618 (2007).

3 A. Nayebi, O. Bartier, G. Mauvoisin and R. El Abdi: New method to determine the mechanical properties of heat treated steels. Int. J. Mech. Sci. 43, 2679 (2001).

4 A. Nayebi, R. El Abdi, O. Bartier and G. Mauvoisin: Hardness profile analysis of elastoplastic heat-treated steels with a gradient in yield strength. Mat. Sci. and Eng. A. 333, 160 (2002).

5 A. Nayebi, R. El Abdi, O. Bartier, G. Mauvoisin: New procedure to determine steel mechanical parameters from the spherical indentation technique. Mech. Mater. 34, 243 (2002).

6 S. Kucharski and Z. Mröz: Identification of plastic hardening parameters of metals from spherical indentation tests. Mat. Sci. and Eng. A. 318, 65 (2001).

7 Y-P. Cao and J. Lu: A new method to extract the plastic properties of metal materials from an instrumented spherical indentation loading curve. Acta Mater. 52, 4023 (2004).

8 H. Lee, J.H. Lee and G. M. Pharr: A numerical approach to spherical indentation techniques for material property evaluation. J. Mec. Phy. Sol. 53, 2037 (2005).

9 M. Beghini, L. Bertini and V. Fontanari: Evaluation of the stress-strain curve of metallic materials by spherical indentation. Int. J. Sol. Struct. 43, 2441 (2006). 
M. Zhao, N. Ogasawara, N. Chiba and X-A. Chen: new approach to measure the elasticplastic properties of bulk materials using spherical indentation. Acta mater. 54, 23 (2006).

11 Y. Cao, X. Qian and N. Huber: Spherical indentation into Elastoplastic materials : indentation-response based definitions of the representative strain. Mat. Sci. and Eng. A. 454, 1 (2007).

12 J-M. Collin, G. Mauvoisin, O. Bartier, R. El Abdi and P. Pilvin: Experimental evaluation of the stress-strain curve by continuous indentation using different indenter shapes. Mat. Sci. and Eng A. 501, 140 (2009).

13 J.-M. Collin, T. Parenteau, G. Mauvoisin and P. Pilvin: Material parameters identification using experimental continuous indentation for cyclic hardening. Comput .Mat. Sci. 46, $333(2009)$.

14 J.-M. Collin, G. Mauvoisin and P. Pilvin: Materials characterization by instrumented indentation using two different approaches. Mat. Design. 31, 636 (2010). P. Jiang, T-H. Zhang, Y-H. Feng, and N-G. Liang: Determination of plastic properties by instrumented spherical indentation:Expanding cavity model and similarity solution approach. J. Mater.Res. 24, 1045 (2009).

16 N. Ogasawara, N. Chiba and X. Chen: A simple framework of spherical indentation for measuring elastoplastic properties. Mech. Mater. 41, 1025 (2009).

17 M. Bocciarelli, G. Bolzon and G. Maier: Parameter identification in anisotropic elastoplasticity by indentation and imprint mapping. Mech. Mater. 37, 855, (2005).

18 A. Yonezu, K. Yoneda, H. Hirakata, M. Sakihara and K. Minoshima: A simple method to evaluate anisotropic plastic properties based on dimensionless function of single spherical indentation - Application to SiC whisker-reinforced aluminium alloy. Mat. Sci. and Eng. A.. 527, $7646(2010)$. 
19 K-H. Chung, W. Lee, J-H. Kim, C. Kim and S-H. Park, D. Kwon and K. Chung: Characterization of mechanical properties by indentation tests and FE analysis validation by application to a weld zone of DP590 steel, Int. Journal of Sol. and Struct. 46, 344 (2009).

20 Hertz H: Uber die Berührung festischer Körper. J. Reine und Angew. Math. 92, 156 (1881).

21 G. Mauvoisin. "Continuous or instrumented indentation device with convex bearing surface and use therefore, particularly for metal sheet indentation". French patent FR2936056. International Patent WO2010029179 (A1) - 2010-03-18 // FR20080056192 15.09.2008 